\title{
PENGENDALIAN PERSEDIAAN BAHAN BAKU OBAT DENGAN MENGGUNAKAN METODE EOQ PROBABILISTIK BERDASARKAN PERAMALAN EXPONENTIAL SMOOTHING PADA PT. XYZ
}

\author{
Fila Dristiana, Tedjo Sukmono \\ Program Studi Teknik Industri \\ Universitas Muhammadiyah Sidoarjo \\ fila_ctk@yahoo.com
}

\begin{abstract}
PT. XYZ is one of the manufactures of parmacheutical. Problems which often appeared are surplus and shortage material. Inventory material control not optimum because order only esimate. With exponential smoothing method can be devise of demand next period and EOQ Probabilistic for to know economic order quantity, total safety stock and reorder point so can minimization inventory cost. Purpose of research are to know exponential smoothing method what representatif for manufacture and give recomendation of this research. Results of research are exponential smoothing method representatif for manufacture and EOQ probabilistic method for Antalgin, Paracetamol and Piroxicam material are economic order quantity in the amount of $313 \mathrm{~kg}, 928 \mathrm{~kg}$ and $33 \mathrm{~kg}$, safety stock $160 \mathrm{~kg}, 403 \mathrm{~kg}$ and $2 \mathrm{~kg}$ and reorder point $325 \mathrm{~kg}$, $1080 \mathrm{~kg}$ dan $14 \mathrm{~kg}$. So total inventory cost of Antalgin, Paracetamol and Piroxicam material in the amount of Rp.3.847.146, Rp.5.025.081 and Rp.1.932.255.
\end{abstract}

Keyword : Inventory, Exponential Smoothing, EOQ Probabilistic

\begin{abstract}
ABSTRAK
PT. XYZ adalah salah satu perusahaan yang bergerak di bidang farmasi. Permasalahan yang sering dihadapi adalah kelebihan dan kekurangan bahan baku. Pengendalian persediaan bahan baku PT. XYZ belum optimal dikarenakan pemesanan bahan baku hanya dengan perkiraan. Dengan metode exponential smoothing dapat merencanakan demand yang akan datang dan EOQ Probabilistik untuk mengetahui seberapa besar jumlah pemesanan optimal, jumlah persediaan cadangan dan titik pemesanan ulang sehingga dapat meminimalkan biaya persediaan. Tujuan penelitian ini untuk mengetahui metode peramalan exponential smoothing apakah representatif atau sesuai untuk perusahaan dan memberikan rekomendasi terkait penelitian ini. Hasil dari penelitian ini adalah metode peramalan exponential smoothing representatif atau sesuai digunakan untuk perusahaan dan dengan menggunakan metode EOQ probabilistik untuk bahan baku Antalgin, Paracetamol dan Piroxicam adalah jumlah pemesanan sebesar $313 \mathrm{~kg}, 928 \mathrm{~kg}$ dan $33 \mathrm{~kg}$, persediaan cadangan $160 \mathrm{~kg}, 403 \mathrm{~kg}$ dan 2kg, dan saat pesan ulang sebesar $325 \mathrm{~kg}, 1080 \mathrm{~kg}$ dan $14 \mathrm{~kg}$. Sehingga biaya total persediaan yang dikeluarkan oleh perusahaan untuk bahan baku Antalgin, Paracetamol dan Piroxicam adalah Rp.3.847.146, Rp.5.025.081 dan Rp.1.932.255.
\end{abstract}

Kata kunci : Persediaan, Exponential Smoothing, EOQ Probabilistik

\section{PENDAHULUAN}

Dalam persaingan di era global, banyak perusahaan yang berlomba untuk memenuhi persediaan yang dibutuhkan oleh konsumen. Setiap perusahaan harus melakukan perbaikan dalam sistem manajemennya, khususnya dalam hal persediaan bahan baku supaya proses produksi berjalan dengan lancar. Salah satu penyebab sistem produksi tidak berjalan dengan baik adalah tidak tersedianya bahan baku untuk kebutuhan produksi.

Pengendalian persediaan bahan baku PT. XYZ belum optimal dikarenakan pemesanan bahan baku hanya dengan perkiraan. Dengan demand yang fluktuatif dan lead time yang 
tidak pasti, mengakibatkan kondisi persediaan yang kurang stabil. Menurut Sutarman 2003, kebutuhan akan sistem pengendalian persediaan bahan baku pada dasarnya muncul karena adanya permasalahan yang mungkin dihadapi oleh perusahaan berupa terjadinya kelebihan atau kekurangan persediaan [3].

PT. XYZ adalah perusahaan yang bergerak di bidang farmasi atau obat-obatan. Bahan baku yang sering mengalami kelebihan dan kekurangan persediaan adalah Antalgin, Paracetamol dan Piroxicam. Untuk mengatasi permasalahan ini, metode yang digunakan adalah exponential smoothing dan EOQ Probabilistik.

\section{LANDASAN TEORI}

\section{A. Peramalan}

Peramalan (forecasting) adalah seni dan ilmu untuk memperkirakan kejadian dimasa depan. Hal ini dapat dikakukan dengan melibatkan pengambilan data masa lalu dan menempatkannya kemasa akan datang dengan suatu bentuk model matematis. Bila juga merupakan prediksi intuasi yang bersifat subjektif. Atau bisa juga dengan menggunakan kombinasi model matematis yang disesuaikan dengan pertimbangan yang baik dari seorang manajer [5].

\section{Exponential Smoothing}

Salah satu metode peramalan dengan menggunakan analisa deret waktu (Ishak, Aulia, 2010 ) [7] adalah metode exponential smoothing. Pada metode ini mempertimbangkan bobot data-data sebelumnya dengan estimasi untuk $\mathrm{Y}^{\prime}(\mathrm{t}+1)$ dengan periode $(\mathrm{t}+1)$ dihitung sebagai:

$$
F S D_{t+1}=\alpha \cdot\left(F_{t}\right)+(1-\alpha) \cdot F S D_{t-1}
$$

Dimana :

$\mathrm{FSD}_{\mathrm{t}+1}=$ Peramalan double exponensial smoothing

$\alpha \quad=$ Faktor pemulusan

$\mathrm{F}_{\mathrm{t}} \quad=$ Peramalan pada periode- $\mathrm{t}$

$\mathrm{FSD}_{\mathrm{t}+1}=$ Peramalan double exponensial smoothing sebelumnya

\section{Galat Error Peramalan}

Implementasi peramalan dalam perencanaan produksi membutuhkan parameter penerimaan. Parameter dalam bentuk ukuran- ukuran kesalahan atau galat error dari hasil peramalan. Besarnya kesalahan pada periode ke-i $\left(\mathrm{e}_{\mathrm{i}}\right)$ dinyatakan sebagai berikut [10] :

$$
e_{i}=X_{i}-F_{i}
$$

Dengan :

$\mathrm{e}_{\mathrm{i}}=$ Kesalahan pada periode ke- $\mathrm{i}$

$\mathrm{X}_{\mathrm{i}}=$ Data aktual periode ke-i

$\mathrm{F}_{\mathrm{i}}=$ Nilai peramalan ke-i

Beberapa statistik ukuran- ukuran akurasi hasil peramalan yang dapat dipakai diantaranya adalah [10]:

1. Mean Absolute Deviation $(M A D)$

$$
M A D=\Sigma\left|\frac{A_{t}-f_{t}}{n}\right|
$$

Dimana :

$\mathrm{A}=$ Permintaan aktual pada periode- $\mathrm{t}$

$\mathrm{F}_{\mathrm{t}}=$ Peramalan permintaan ( forecast) pada periode- $\mathrm{t}$

$\mathrm{n}=$ Jumlah periode peramalan yang terlibat

2. Mean Square Error (MSE)

$$
M S E=\sum \frac{\left(A_{t}-F_{t}\right)^{2}}{n}
$$


3. Mean Absolute Percentage Error (MAPE)

$$
M A P E=\left(\frac{100}{n}\right) \Sigma\left|A_{t}-\frac{F_{t}}{A_{t}}\right|
$$

4. Mean Forecast Error (MFE).

$$
M F E=\sum \frac{\left(A_{t}-F_{t}\right)}{n}
$$

\section{Sinyal Penelusuran (Tracking Signal)}

Sinyal penelusuran dihitung sebagai running sum of the forecast errors (RSFE) dibagi dengan mean absolute deviation (MAD ) [5]:

$$
\text { Trackingsignal }=\frac{R S F E}{M A D}
$$

dimana RSFE adalah permintaan actual pada periode ke-i - ramalan permintaan pada periode ke-i

\section{Verifikasi Hasil Peramalan}

Harga moving range menurut Ginting, 2007 [10] diperoleh dari :

$$
\begin{aligned}
\overline{M R} & =\frac{\sum_{2}^{n} M R_{t}}{n-1} \\
M R_{t} & =\left|\left(y_{t}^{\prime}-y_{t}\right)-\left(y_{t-1}^{\prime}-y_{t-1}^{\prime}\right)\right|
\end{aligned}
$$

Batas kendali atas dan bawah pada peta moving range adalah :

$$
\begin{aligned}
& \mathrm{BKA}=\mathrm{UCL}=+2,66 \mathrm{MR} \\
& \mathrm{BKB}=\mathrm{LCL}=-2,66 \mathrm{MR}
\end{aligned}
$$

\section{B. Persediaan}

Persediaan menurut S. Assauri adalah suatu aktiva yang meliputi barang-barang milik perusahaan yang dimaksud untuk dijual dalam satu periode usaha yang normal atau persediaan bahan baku yang menunggu penggunaannya dalam suatu proses produksi [6].

\section{Model Persediaan}

Persediaan dari tingkat permintaan dan periode kedatangan pesanan, model persediaan dibedakan menjadi [13] :

1. Model Persediaan Deterministik

Model ini ditandai oleh karakteristik permintaan dan waktu kedatangan pesanan yang dapat diketahui sebelumnya secara pasti.

2. Model Persediaan Probabilistik

Model persediaan probabilitas ditandai oleh perilaku permintaan dan lead time yang tidak dapat diketahui sebelumnya secara pasti sehingga perlu didekati dengan distribusi probabilitas.

\section{EOQ Probabilistik}

Perhitungan EOQ Probabilistik adalah sebagai berikut [13] :

1. Uji normalitas data

Untuk mengetahui data berdistribusi normal atau tidak normal dengan menggunakan uji kolmogorov smirnov [14].

a. Jika signifikansi yang diperoleh $>\alpha$, maka data berdistribusi normal

b. Jika signifikansi yang diperoleh $<\alpha$, maka data tidak berdistribusi normal

2. Menyusun distribusi probabilitas demand dan lead time untuk menentukan harapan demand selama lead time

3. Menentukan Q optimal. 


$$
Q=\sqrt{\frac{2 D\left(S+B K \sum\left(K_{i}-S P\right) P\left(K_{i}\right)\right)}{h}}
$$

Diasumsikan bahwa $\left.\sum(\mathrm{Ki}-\mathrm{SP}) \mathrm{P}(\mathrm{Ki})\right)=0$ sehingga menjadi :

$$
Q=\sqrt{\frac{2 D S}{h}}
$$

Dimana :

D : Kebutuhan dalam suatu periode perencanaan

Q: Jumlah barang yang dipesan setiap kali pesanan dibuat

$\mathrm{S}$ : Biaya yang harus dikeluarkan setiap kali pesanan dibuat

$\mathrm{h}$ : Biaya simpan per unit periode

4. Menentukan peluang kehabisan persediaan

$$
P(K P)=\frac{h \cdot Q}{D \cdot B K P}
$$

5. Menentukan persediaan cadangan dan reorder point

a) Persediaan cadangan adalah faktor keamanan $\mathrm{x} \sigma$

b) Saat pesan ulang adalah persediaan cadangan ditambah harapan pemakaian selama lead time

6. Perhitungan perbandingan Biaya Marginal dengan Penghematan Marginal

$$
M S=\frac{D}{Q} B K P . P(K P)
$$

7. Menghitung Biaya Total Persediaan

Biaya kekurangan persediaan

$$
B K P=\frac{D}{Q} B K \Sigma\left(K_{i}-S P\right) P\left(K_{i}\right)
$$

Biaya simpan untuk persediaan cadangan :

$$
B S=h(S P-H P)
$$

Biaya Total Persediaan

$$
B T P=\frac{D}{Q} S+\frac{Q}{2} h+B S+B K P
$$

\section{METODELOGI PENELITIAN}

Untuk mempermudah agar proses penelitian tidak meluas di luar pembahasan, maka dibuat diagram alir penelitian seperti pada gambar 1.

\section{HASIL DAN PEMBAHASAN}

\section{A. Peramalan Exponential Smoothing}

Hasil peramalan menggunakan metode exponential smoothing dengan bantuan Software Pom for windows dapat dilihat pada tabel 1 


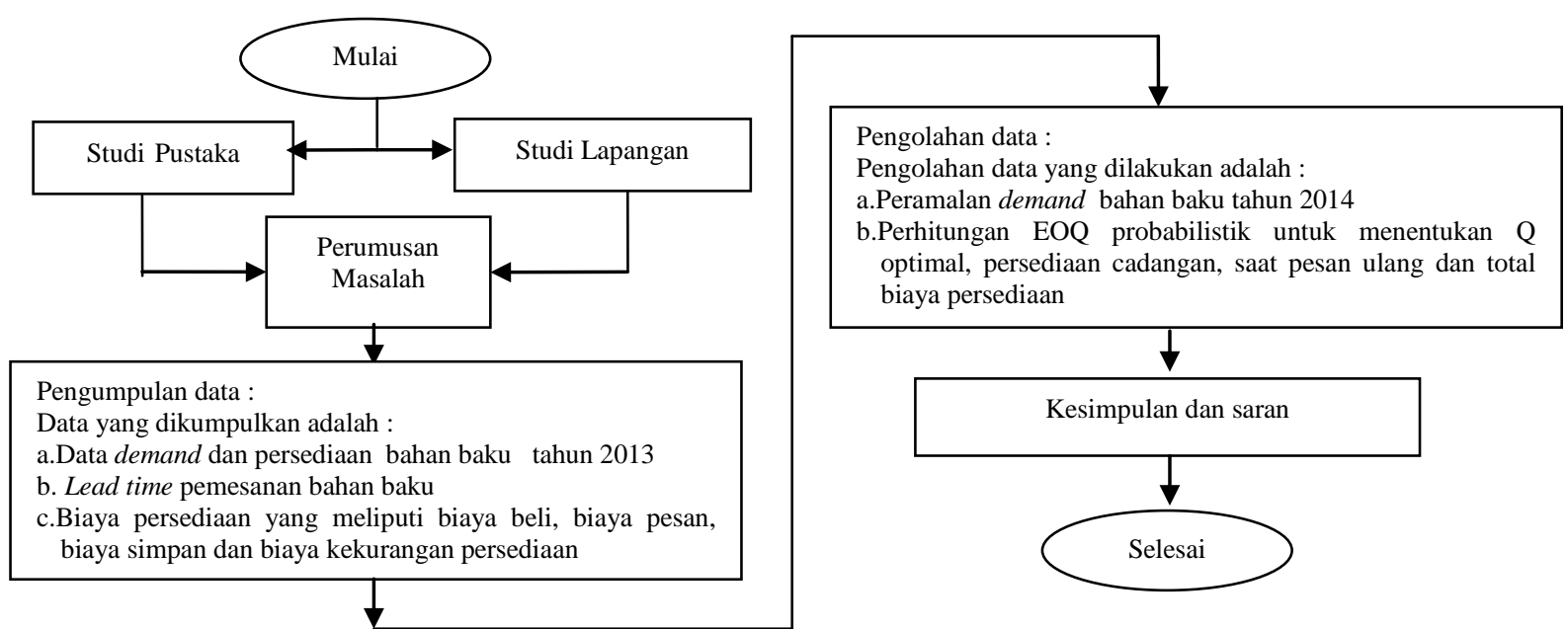

Gambar 1. Diagram Alir Penelitian

Tabel 1. Output Hasil Peramalan Bahan Baku Obat Tahun 2014

\begin{tabular}{|l|r|r|r|}
\hline \multirow{2}{*}{ Bulan } & \multicolumn{3}{|c|}{ Hasil Peramalan } \\
\cline { 2 - 4 } & Antalgin & Paracetamol & Piroxicam \\
\hline Januari & 1000 & 5500 & 90 \\
\hline Februari & 1655,5 & 6526,06 & 92,34 \\
\hline Maret & 1651,71 & 5970,38 & 92,31 \\
\hline April & 1374,53 & 6058,42 & 94,8 \\
\hline Mei & 1185,1 & 6521,5 & 92,39 \\
\hline Juni & 1747,38 & 5580,07 & 96,13 \\
\hline Juli & 1783,69 & 5496,04 & 96,12 \\
\hline Agustus & 1380,94 & 5504 & 99,35 \\
\hline September & 1083,59 & 4656,44 & 99,05 \\
\hline Oktober & 956,91 & 4823,42 & 98,24 \\
\hline November & 986,64 & 4455,32 & 98,75 \\
\hline Desember & 1064,86 & 3883,15 & 100,31 \\
\hline
\end{tabular}

Pada tabel 1 di atas $\alpha$ pemulusan terbaik untuk bahan baku Antalgin, Paracetamol dan Piroxicam adalah 0,69, 0,42 dan 0,09. Dari hasil verifikasi peramalan dinyatakan bahwa hasil masih dalam batas kontrol, maka peramalan dengan metode exponential smoothing dapat digunakan.

\section{B. Perhitungan EOQ Probabilistik}

\section{Uji Distribusi Demand Bahan Baku}

Sebelum melakukan perhitungan EOQ Probabilistik. Data yang digunakan harus berdistribusi normal. Pengujian distribusi demand bahan baku obat menggunakan distribusi normal Kolmogorov- Smirnov dengan bantuan Software SPSS.

Pengujian hipotesis :

a. Taraf signifikansi uji $(\alpha)=0,05$

b. Jika signifikansi yang diperoleh $>\alpha$, maka data berdistribusi normal

c. Jika signifikansi yang diperoleh $<\alpha$, maka data tidak berdistribusi normal

Pada hasil uji Kolmogorov-Smirnov Test untuk bahan baku Antalgin, Paracetamol dan Piroxicam diperoleh nilai signifikansi 0,660, 0,614 dan 0,714. Hasil yang diperoleh $>0,05$, jadi data berdistribusi normal. 


\section{Menyusun Distribusi Probabilitas Demand dan Lead Time untuk Menentukan Harapan Demand Selama Lead Time}

Lead time pada perusahaan ini membutuhkan waktu 3 sampai 4 hari pada saat memesan bahan baku hingga pesanan diterima oleh perusahaan.

Harapan demand selama lead time = Harapan demand /bulan $\mathrm{x}$ harapan Lead time Jadi, Harapan demand selama lead time masing - masing bahan baku adalah :
a. Antalgin $=1322,57 \times 0,125$
$=165,321$
b. $\quad$ Paracetamol $=5414,567 x$ 0,125
$=676,821$
c. Piroxicam $=95,816 \times 0,125$
$=11,977$

\section{Menentukan Q Optimal}

\section{a. Antalgin}

Perhitungan Q optimal :

$$
Q=\sqrt{\frac{2 D\left(S+B K \sum\left(K_{i}-S P\right) P\left(K_{i}\right)\right)}{h}}
$$

Diasumsikan bahwa $\left.\sum(\mathrm{Ki}-\mathrm{SP}) \mathrm{P}(\mathrm{Ki})\right)=0$ sehingga menjadi

$$
\begin{gathered}
Q=\sqrt{\frac{2 D S}{h}} \\
Q=\sqrt{\frac{2(15870,85)(25000)}{8136}}=312,3(\text { dibulatkan menjadi } 313 \mathrm{~kg}
\end{gathered}
$$

b. Paracetamol

Perhitungan Q optimal :

$$
Q=\sqrt{\frac{2 D\left(S+B K \sum\left(K_{i}-S P\right) P\left(K_{i}\right)\right)}{h}}
$$

Diasumsikan bahwa $\left.\sum(\mathrm{Ki}-\mathrm{SP}) \mathrm{P}(\mathrm{Ki})\right)=0$ sehingga menjadi

$$
\begin{gathered}
Q=\sqrt{\frac{2 D S}{h}} \\
Q=\sqrt{\frac{2(64974,8)(25000)}{3776}}=927,55 \text { dibulatkan menjadi } 928 \mathrm{~kg}
\end{gathered}
$$

c. Piroxicam

Perhitungan Q optimal :

$$
Q=\sqrt{\frac{2 D\left(S+B K \sum\left(K_{i}-S P\right) P\left(K_{i}\right)\right)}{h}}
$$

Diasumsikan bahwa $\left.\sum(\mathrm{Ki}-\mathrm{SP}) \mathrm{P}(\mathrm{Ki})\right)=0$ sehingga menjadi

$$
Q=\sqrt{\frac{2 D S}{h}}
$$




$$
Q=\sqrt{\frac{2(1149,79)(25000)}{55262}}=32,254 \text { dibulatkan menjadi } 33 \mathrm{~kg}
$$

Jadi, Q optimal untuk bahan baku Antalgin, Paracetamol dan Piroxicam adalah 313 kg, 928 kg dan 33 kg

\section{Perhitungan $\mathbf{P ( K P )}$ Optimal}

a. Antalgin

$$
\begin{aligned}
& P(K P)=\frac{h \cdot Q}{D \cdot B K P} \\
& P(K P)=\frac{8136 \times 312,305}{15870,85 \times 25425} \\
& P(K P)=0,0063
\end{aligned}
$$

Pada tabel kurva normal $\mathrm{P}(\mathrm{KP})=0,0063$ terletak antara nilai 0,0040 pada $\mathrm{z}=$ 0,51 dan nilai 0,0080 pada $\mathrm{z}=0,52$.

Selisih antara nilai yang dicari 0,0063 dengan nilai terdekat 0,0080 adalah 0,0017 . Perbandingan nilai $\mathrm{z}$ dengan nilai probabilitas adalah 2,5 , maka nilai $\mathrm{z}$ yang dicari adalah $(2,5 \times 0,0017)+0,52=0,5243$.

Jadi, nilai z atau faktor keamanan untuk bahan baku Antalgin adalah 0,5243

b. Paracetamol

$$
\begin{aligned}
& P(K P)=\frac{h \cdot Q}{D \cdot B K P} \\
& P(K P)=\frac{3776 \times 927,559}{64974,8 \times 11800} \\
& P(K P)=0,0046
\end{aligned}
$$

Pada tabel kurva normal $\mathrm{P}(\mathrm{KP})=0,0046$ terletak antara nilai 0,0040 pada $\mathrm{z}=$ 0,51 dan nilai 0,0080 pada $\mathrm{z}=0,52$.

Selisih antara nilai yang dicari 0,0046 dengan nilai terdekat 0,0040 adalah 0,0006 . Perbandingan nilai $\mathrm{z}$ dengan nilai probabilitas adalah 2,5 , maka nilai $\mathrm{z}$ yang dicari adalah $(2,5 \times 0,0006)+0,51=0.511420537$.

Jadi nilai z atau faktor keamanan untuk bahan baku Paracetamol adalah 0,5114

c. Piroxicam

Perhitungan $\mathrm{P}(\mathrm{KP})$ optimal

$$
\begin{aligned}
& P(K P)=\frac{h \cdot Q}{D \cdot B K P} \\
& P(K P)=\frac{55262 \times 32,254}{1149,79 \times 172695} \\
& P(K P)=0,0089
\end{aligned}
$$

Pada tabel kurva normal $\mathrm{P}(\mathrm{KP})=0,0089$ terletak antara nilai 0,0080 pada $\mathrm{z}=$ 0,52 dan nilai 0,0120 pada $\mathrm{z}=0,53$.

Selisih antara nilai yang dicari 0,0089 dengan nilai terdekat 0,0080 adalah 0,0009 . Perbandingan nilai z dengan nilai probabilitas adalah 2,5 , maka nilai z yang dicari adalah $(2,5 \times 0,0009)+0,52=0.522441366$.

Jadi nilai z atau faktor keamanan untuk bahan baku Piroxicam adalah 0,5224

\section{Penghitungan Persediaan Cadangan dan Saat Pesan Ulang}

a. Antalgin

Persediaan cadangan $=$ faktor keamanan $\mathrm{x} \sigma$

$$
=0,5243 \times 304,33
$$


= 159,549 dibulatkan menjadi 160

Saat pesan ulang $=$ Persediaan cadangan + harapan pemakaian selama lead time

$=159,549+165,321$

= 324,87 dibulatkan menjadi 325

Jadi, persediaan cadangan dan saat pesan ulang untuk bahan baku Antalgin adalah $160 \mathrm{~kg}$ dan $325 \mathrm{~kg}$.

b. Paracetamol

Persediaan cadangan $=$ faktor keamanan $\mathrm{x} \sigma$

$=0,5114 \times 786,5072$

$=402,236$ dibulatkan menjadi 403

Saat pesan ulang $=$ Persediaan cadangan + harapan pemakaian selama lead time

$=402,236+676,821$

$=1079,057$ dibulatkan menjadi 1080

Jadi, persediaan cadangan dan saat pesan ulang untuk bahan baku Paracetamol adalah $403 \mathrm{~kg}$ dan $1080 \mathrm{~kg}$.

c. Piroxicam

Persediaan cadangan $=$ faktor keamanan $\mathrm{x} \sigma$

$=0,5224 \times 3,276$

$=1,711$ dibulatkan menjadi 2

Saat pesan ulang $=$ Persediaan cadangan + harapan pemakaian selama lead time

$=1,711+11,977$

= 13,688 dibulatkan menjadi 14

Jadi, persediaan cadangan dan saat pesan ulang untuk bahan baku Piroxicam adalah $2 \mathrm{~kg}$ dan $14 \mathrm{~kg}$.

\section{Perhitungan perbandingan Biaya Marginal dengan Penghematan Marginal}

a. Antalgin

$$
\begin{aligned}
M S & =\frac{D}{Q} B K P . P(K P) \\
M S & =\frac{15870.85}{312.305} 25432.0,0063 \\
M S & =8136
\end{aligned}
$$

Jadi, terbukti bahwa $\mathrm{P}(\mathrm{KP})$ atau probabilitas kehabisan persediaan optimal yaitu $47,57 \%$ menjamin keseimbangan antara penambahan persediaan cadangan untuk menjaga kemungkinan kehabisan persediaan dengan penghematan yang diharapkan.

b. Paracetamol

$$
\begin{aligned}
M S & =\frac{D}{Q} B K P . P(K P) \\
M S & =\frac{64974,8}{927,5589} 11800.0,0046 \\
M S & =3776
\end{aligned}
$$

Jadi, terbukti bahwa $\mathrm{P}(\mathrm{KP})$ atau probabilitas kehabisan persediaan optimal yaitu 48,86\% menjamin keseimbangan antara penambahan persediaan cadangan untuk menjaga kemungkinan kehabisan persediaan dengan penghematan yang diharapkan. 
c. Piroxicam

$$
\begin{aligned}
M S & =\frac{D}{Q} B K P . P(K P) \\
M S & =\frac{1149,79}{32,2538} 172695.0,0089 \\
M S & =55262
\end{aligned}
$$

Jadi, terbukti bahwa $\mathrm{P}(\mathrm{KP})$ atau probabilitas kehabisan persediaan optimal yaitu 47,76\% menjamin keseimbangan antara penambahan persediaan cadangan untuk menjaga kemungkinan kehabisan persediaan dengan penghematan yang diharapkan.

\section{Menghitung Biaya Total Persediaan}

a. Antalgin

1. Biaya simpan untuk persediaan cadangan :

$$
\begin{aligned}
& B S=h(S P-H P) \\
& B S=8136(324,87-165,32) \\
& B S=R p 1.298 .093
\end{aligned}
$$

2. Biaya kekurangan persediaan

$$
\begin{aligned}
& B K P=\frac{D}{Q} B K \Sigma\left(K_{i}-S P\right) P\left(K_{i}\right) \\
& B K P=\frac{15870,85}{312,305} 25425(0,0063) \\
& B K P=R p 8.136
\end{aligned}
$$

3. Biaya Total Persediaan

$$
\begin{aligned}
& B T P=\frac{D}{Q} S+\frac{Q}{2} h+B S+B K P \\
& B T P=\frac{15870,85}{312,305}(25000)+\frac{312,305}{2}(8136)+1.298 .093+8136 \\
& B T P=R p 3.847 .135
\end{aligned}
$$

Jadi, biaya total persediaan untuk bahan baku Antalgin adalah Rp. 3.847.146

b. Paracetamol

1. Biaya simpan untuk persediaan cadangan :

$$
\begin{aligned}
& B S=h(S P-H P) \\
& B S=3776(1079,056-676,8208) \\
& B S=R p 1.518 .843
\end{aligned}
$$

2. Biaya kekurangan persediaan

$$
\begin{aligned}
& B K P=\frac{D}{Q} B K \Sigma\left(K_{i}-S P\right) P\left(K_{i}\right) \\
& B K P=\frac{64974,8}{927,5588} 11.800(0,0046) \\
& B K P=R p 3.776
\end{aligned}
$$


3. Biaya Total Persediaan

$$
\begin{aligned}
& B T P=\frac{D}{Q} S+\frac{Q}{2} h+B S+B K P \\
& B T P=\frac{64974,8}{927,5588}(25.000)+\frac{927,5588}{2}(3.776)+1.518 .843+3.776
\end{aligned}
$$

$B T P=R p 5.025 .081$

Jadi, biaya total persediaan untuk bahan baku Paracetamol adalah Rp.

5.025 .081

c. Piroxicam

1. Biaya simpan untuk persediaan cadangan :

$$
\begin{aligned}
& B S=h(S P-H P) \\
& B S=55262(13,688-11,9769) \\
& B S=R p 94583,07
\end{aligned}
$$

2. Biaya kekurangan persediaan

$$
\begin{aligned}
B K P & =\frac{D}{Q} B K \Sigma\left(K_{i}-S P\right) P\left(K_{i}\right) \\
B K P & =\frac{1149,79}{32,2538} 172.695(0,0089) \\
B K P & =R P 55.262
\end{aligned}
$$

3. Biaya Total Persediaan

$$
\begin{aligned}
& B T P=\frac{D}{Q} S+\frac{Q}{2} h+B S+B K P \\
& B T P=\frac{1149,79}{32,2538}(25.000)+\frac{32,2538}{2}(55.262)+94.583,07+55.262 \\
& B T P=R P 1.932 .255
\end{aligned}
$$

Jadi, biaya total persediaan untuk bahan baku Piroxicam adalah Rp. 1.932.255

\section{KESIMPULAN DAN SARAN}

\section{A. Kesimpulan}

Kesimpulan yang diperoleh dari analisa pengendalian persediaan bahan baku adalah :

1. Hasil metode peramalan exponential smoothing representatif atau sesuai untuk perusahaan yang ditunjukkan pada verifikasi peramalan masih dalam BKA dan BKB.

2. Rekomendasi yang digunakan adalah:

Dengan menggunakan metode EOQ Probabilistik, perusahaan dapat melakukan pemesanan bahan baku Antalgin, Paracetamol dan Piroxicam adalah sebesar 313 $\mathrm{kg}, 928 \mathrm{~kg}$ dan $33 \mathrm{~kg}$. Jumlah bahan baku untuk persediaan cadangan Antalgin, Paracetamol dan Piroxicam adalah $160 \mathrm{~kg}, 403 \mathrm{~kg}$ dan 2kg. Dan melakukan pemesanan kembali jika jumlah bahan baku Antalgin, Paracetamol dan Piroxicam telah mencapai jumlah sebesar $325 \mathrm{~kg}, 1080 \mathrm{~kg}$ dan $14 \mathrm{~kg}$. Sehingga biaya total persediaan yang dikeluarkan oleh perusahaan untuk bahan baku Antalgin, Paracetamol dan Piroxicam adalah Rp.3.847.146, Rp.5.025.081 dan Rp.1.932.255. 


\section{B. Saran}

Saran yang diberikan berdasarkan penelitian yang sudah dilakukan adalah :

1. Penelitian ini bisa dikembangkan dengan menggunakan metode lain yang sesuai sehingga bisa dibandingkan untuk memperoleh hasil yang lebih baik.

2. Untuk penelitian selanjutnya sebaiknya mempertimbangkan jumlah supplier bahan baku karena peran supplier dapat mempengaruhi ketersediaan bahan baku

\section{DAFTAR PUSTAKA}

[1] Ardhiani, T.I and Tanuwijaya, H, 2009, Sistem Pendukung Keputusan Pengadaan Supplies dengan Metode Single Exponential Smoothing dan Double Moving Average (Studi Kasus Rumah Sakit Siti Khodijah Sepanjang ), Jurnal SNASTI, hal 235 - 243.

[2] Danniel, Frans, 2011, Pengendalian Persediaan Bahan Baku di PT. Kimia Farma (Persero) Tbk Plant Medan Menggunakan Metode EOQ Probabilistik, Tugas akhir, Universitas Sumatera Utara.

[3] Ernawati, Y, 2008, "Sistem Pengendalian Persediaan Model Probabilistik dengan "Back Order Policy”, Jurnal Matematika, vol. 11, no.2, hal 87-93, ISSN 1410-8518

[4] Hapsari, V, Y., and Susty A, 2013, "Evaluasi Perencanaan Persediaan Bahan Baku Tepung Terigu Menggunakan EOQ ( Economic Order Quantity) Model Probabilistik Pada PT. Dika Bakery, Jurnal Ilmiah Akutansi, PP 1-11.

[5] Heizer, J., and Render. B, 2006, "Manajemen Operasi”, Edisi ketujuh, Penerbit Salemba Empat, Jakarta

[6] Indroprasto, and Suryani. E, 2012, “ Analisis Pengendalian Persediaan Produk dengan metode EOQ menggunakan Algoritma Genetika untuk Mengefisienkan Biaya Persediaan”, Jurnal Teknik ITS, vol. 1, hal 305-309.

[7] Marie, I,A, Ariyanti, S and Tangel, M, 2013, Usulan Perencanaan Kebutuhan Bahan Baku di PT. KMT, Jurnal Ilmiah Teknik Industri, vol. 1, no. 2, 75 - 85

[8] Meilani.D.,and Saputra.R.E, 2013, "Pengendalian Persediaan Bahan Baku Vulkanisir Ban”, Jurnal Optimasi Sistem Industri, vol. 12, no. 1,hal 326-334.

[9] Nasution.A.H, 2003, “ Perencanaan \& Pengendalian Produksi”, Institut Teknologi Sepuluh November, $2^{\text {nd }}$ edition.

[10] Rahmayanti.D.,and Fauzan.A, 2013, “ Optimalisasi Sistem Persediaan Bahan Baku Karet Mentah ( Lateks ) dengan Metode Lot Sizing, Jurnal Optimasi Sistem Industri, vol 12, no 1, hal 317-325.

[11] Sahara, A, 2013, “ Sistem Peramalan Persediaan Unit Mobil Mitsubishi pada PT. Sardana Indah Berlian Motor dengan Menggunakan Metode Exponential Smoothing, Majalah Ilmiah Informasi dan Teknologi Ilmiah ( NTI), volume 1, no 1, hal 1-7.

[12] Sahli.M, 2013, " Penerapan Metode Exponensial Smoothing dalam Sistem Informasi Pengendalian Persediaan Bahan Baku ( Study kasus toko Tirta Harum)”. Jurnal Simetris, vol. 3, no. 1, hal 59-70.

[13] Siswanto, 2007, “Operation Research”, Penerbit Erlangga, Jakarta.

[14] Widarta Yasa, M, 2014, "Pengaruh Pelatihan Plaiometrik Side Shop dan Double Leg Bound Terhadap Daya Ledak ( Power ) Otot Tungkai”, e-Journal IKOR, vol 1. 
